DOI 10.37882/2500-3682.2020.08.10

\title{
СИМВОЛИЗМ КАК ФИЛОСОФСКОЕ И ХУДОЖЕСТВЕННОЕ ОСНОВАНИЕ КУЛЬТУРЫ «СЕРЕБРЯНОГО ВЕКА»
}

\section{SYMBOLISM AS A PHILOSOPHICAL AND ARTISTIC BASIS OF THE "SILVER AGE" CULTURE}

N. Kovalenko

Summary: This work is devoted to analysis of the Foundation of human society - the beginning of spiritual. In society there is increasing recognition of the idea that developed in the different epochs of Russian history, eminent philosophers, scientists and writers, that without the recognition of Absolutes, ideals and moral prohibitions, without following the universal norms and principles, and most importantly, without the idealization and the symbolization of sticking to the past in everyday life, it is impossible for spiritual revival and moral purification of society and the individual. Thus, come together ideas about spiritual, moral, and religious - Orthodox and symbolic in philosophical outlook, artistic and aesthetic culture.

Keywords: spirituality, moral values, Russian religious philosophers, symbol, symbolism, spiritual culture.
$\mathrm{P}$ усские религиозные философы - от славянофилов и В. Соловьева до С. Франка, С. Булгакова, Г. Флоровского, П. Флоренского и других - были глубоко убеждены в том, что в основе фундамента человеческого общества заложено начало духовное. Саму духовность они рассматривали как важнейшую особенность, как символ русской национальной культуры. Общество в состоянии переходности, по их мысли, теряет веру и духовные ориентиры. Духовность в самом широком общефилософском смысле представляет собой особый социальный и культурный феномен, сущность которого состоит в совокупности проявлений духа в мире и человеке. Так это трактуется в философской антропологии и такой ее разновидности как христианская духовная антропология [1]. В социологии, культурологии и публицистике «духовностью» часто называют объединяющие начала общества, выражаемые в виде нравственно-этических ценностей и моральных норм, духовных практик, и проявлений творческих возможностей сконцентрированных, как правило, в религиозных учениях и художественных образах искусства. В рамках такого подхода, проекция духовности в индивидуальном сознании называется совестью, а также утверждается, что укрепление духовности осуществляется в процессе церковной проповеди, просветительской деятельности, идейно-воспитательной и патриотической работы. Современный автор Ю.А. Жданов пишет, осмысливая историю разви-
Коваленко Наталья Геннадьевна

к.ф.н., доцент, Санкт-Петербургский государственный аграрный университет nataly6707@mail.ru

Аннотация: Данная работа посвящена анализу фундамента человеческого общества - началу духовному. В социуме всё большее признание приобретает мысль, развивавшаяся в разные эпохи российской истории выдающимися философами, учеными и писателями, что без признания абсолютов, идеалов и нравственных запретов, без следования общечеловеческим нормам и принципам, а главное, без их идеализации и символизации, неукоснительного следования последним в повседневной жизни, невозможно духовное возрождение и нравственное очищение общества и личности. Таким обра30м, соединяются воедино представления о духовно-нравственном, религи0зно-православном и знаково-символическом в философском мировоззрении и художественно-эстетической культуре.

Ключевые слова: духовность, нравственные ценности, русские религиозные философы, символ, символизм, духовная культура.

тия России и её ведущую духовную ценность - русскую литературу как сердцевину отечественной культуры: «Русская культура - это прежде всего духовность, а духовность - это устремлённость ввысь, к небу. Выше неба нет ничего. Небо рождает богов. Боги определяют наше мировоззрение. Небо - это дух созидающий, придающий смысл человеческому существованию. Русская культура - это величие духа. Русскую культуру можно постичь только целостно: сердцем и головой одновременно. Это не лёгкое дело. Чтобы понять русскую культуру, надо быть самому одухотворённым» [2; С.6]. Такие проникновенные слова человека, отдавшего половину своей жизни культуре и образованию, очень много значат для россиянина. В них сосредоточена всеобъемлющая мысль о великой миссии России, её значимости не только для живущих в ней, но и для других народов и их культур. Русскую литературу создавали люди, обладающие огромной силой воли, духа, любви к людям, к жизни. Они были истинными христианами, познавшими глубокие законы формирования ценностей духовного мира человека.

В теоретико-философской трактовке феномен духовности рассматривается в первую очередь в социокультурном значение. Как пишут сибирские социальные философы, духовность, это «система устойчивых связей человека и общества...способ организации и существо- 
вания ценного (выделено - авт.) начала в содержании общечеловеческого бытия. Выполняя роль универсальной общественной ценности и непременного элемента социокультурной жизни, духовность анализируется в контексте социальных трансформаций» [3; С.169]. То есть в понимании духовности философия также ориентирует внимание исследователя на ценностную составляющую духовности, на ее место и роль в духовной жизни общества.

Духовная жизнь человечества как правило символически противопоставляется и корреспондируется с культурой материальной. Их гармоническое единство и является собственно культурой. Э.С. Маркарян, один из ведущих российских философов-культурологов пишет: «Символизация, будучи одним из важнейших атрибутов культуры, может быть должным образом осмыслена лишь в том случае, когда будет пролит свет на процесс происхождения культуры как целостного феномена» [4].

Если под материальной культурой понимается предметно-физический мир культуры (средства труда, жилище, одежда, обработанные руками человека природные вещества и объекты), то в качестве культуры духовной выступают те явления, которые связаны с сознанием, с интеллектуальной, а также с эмоционально-психологической деятельностью человека. Это в первую очередь язык, а также обычаи и традиции, моральные нормы и нравственные ценности, верования и знания, искусство и т.д. [5]. Такое понимание культуры духовной пришло в отечественную практику из немецкой литературы в XIX веке. Среди английских и французских эволюционистов того периода подобное деление на материальную и духовную культуру было также хорошо распространено. Так, Э. Тайлор в своей знаменитой работе «Первобытная культура» отчётливо подразделяет культуру на две части - «материальную» и «умственную», подразумевая под последней идеи, обычаи, мифы, воззрения и верования [6], то есть основные составляющие духовной жизни.

Отечественные философы, социальные аналитики в дореволюционный период, а также в постреволюционные годы в зарубежном изгнании, широко обращаются к понятию «духовная культура»; оно у них тесно соотнесено с духовной основой общественного бытия. В работах русских авторов конца XIX - первая половина XX века термин «духовная культура» переплетается с такими понятиями, как «духовная жизнь», «сфера духа», «духовное обновление» и др. Во всех указанных понятиях сфера и сущность духовности связывается с объективной, надындивидуальной реальностью, которая символически укоренена в сердце человека, открываясь ему через внутреннее усилие и мистический опыт. Это - реальность Добра, Красоты, Истины и в конечном итоге реальность Бога.
В настоящее время всё большее признание приобретает мысль, развивавшаяся в разные исторические эпохи выдающимися российскими умами, что без признания абсолютов, идеалов и нравственных запретов, без следований общечеловеческим нормам и принципам, а главное, без их идеализации и символизации невозможно духовное возрождение и нравственное очищение общества и личности. Таким образом, соединяются воедино представления о духовно-нравственном, религиозно-православном и знаково-символическом.

Русские мыслители заложили основы мировоззренческого символизма. Одним из столпов русской духовной культуры является выдающийся отечественный философ Владимир Сергеевич Соловьев (1853-1900). С его именем связано появление в России целостного самобытного религиозно - философского мировоззрения. Философия всеединства Соловьева представляет собой яркий пример системы «метафизического синтеза» и подчинена требованию символического универсализма, который выступает новой насущной культурной задачей. С.Н. Булгаков видит в его философии уникальный опыт «универсального синтеза» философии, религии и социальной практики. Характеризуя российское общество начала XX столетия, общество - больное революцией, Булгаков говорит: «Современное сознание, разорванное, превращенное в обрывок самого себя в системе разделения труда, не перестает болеть этой своей разорванностью и ищет целостного мировоззрения, которое бы связывало глубины бытия с повседневной работой, осмысливало бы личную жизнь, ставило бы ее sub specie aetemitatis... Между тем, при всем богатстве знаний и развитии науки, современная мысль представляет картину внутреннего распада и бессилия (выделено - авт.). Те элементы, которые нормально должны находиться в гармонии, теперь враждуют между собою или находятся в состоянии взаимного отчуждения: положительная наука заподазривает метафизику в нарушении своих прав, метафизика вместе с наукой в том же заподазривает религию, а практическая жизнь идет своим порядком, независимо как от той, так и другой» [7; C.389]. Преодоление этой разорванности между сферами должного (идеального) и действительного бытия осуществляется, по мнению Булгакова, в системе метафизики Соловьева.

Еще одна черта соловьевской философии, отмечаемая многими исследователями и ставшая символичной для современной мировой культуры, - это универсализм, проявившийся и в онтологии Соловьева (учение о Всеединстве), и в гносеологии, и в аксиологии, и в историософии, и в философии культуры. Большинство западных исследователей творчества Соловьева отмечают его открытость католицизму и европейской культуре, а также характерную для его философской мысли тенденцию духовного сближения Востока и Запада. Этот 
синтез, по Соловьеву, должен быть основан на твердой вере в единые духовные и символические константы Восточного и Западного христианства и в то, что разделения православной и католической церквей de jure не было. Универсализм Соловьева нашел отражение также и в его социально-философских воззрениях: мессианизм для философа побеждает национализм, поскольку определяется как поиск и выполнение нацией своей уникальной (особой) исторической задачи в общем деле преодоления социальных противоречий и формирования универсального человечества. Символический принцип универсализма с особой силой акцентируется в учении Соловьева о Богочеловечестве, представляющем собой особое духовное единство Абсолюта и человечества. Учение о Богочеловечестве стало одной из наиболее известных тем публичных (лекции) выступлений Соловьева.

Универсализм с точки зрения Соловьева выступает важным свойством культуры, которая рассматривается философом как интегральная форма социально-исторического бытия человечества, синтезирующая в себе: общемировоззренческие принципы и установки с совокупностью способов практического воспроизводства социального пространства. Культура, воплощающая в себе духовное всеединство мира, призвана служить средством приобщения изменчивых конкретно-исторических проявлений бытия личности и человечества к идеальной сущности мира. Именно в культуре происходит актуализация духовной природы человека - рождение личности, также как метафизические основания бытия обретают и социальные общности вплоть до человечества.

Многие исследователи соловьевского творчества [8], [9], [10], [11] [12] указывают на два «гносеологических корня» его философии, исходящих из учения о цельности знания. Н.А. Бердяев писал о философе: «Мистик и схоластик-рационалист вечно боролись в Соловьеве» [13; С.363]. В соловьевском понимании познавательными началами, формирующими мировидение человека, являются разум и вера, предлагающие два пути к достижению истины - рациональный и мистический. Если разум раскрывает имманентное, предлагая схему объяснения, метод описания и принцип классификации объекта, то есть действуя согласно предписаниям научного исследования, то вера посредством мистического опыта и духовного напряжения позволяет преодолеть границы имманентного (действительного) и обнаруживает в нем присутствие трансцендентного (сверх-действительного) начала.

Именно вера, по Соловьеву, открывает их единство, подлинная природа которого может быть познана только соединением рациональной деятельности и интуиции. Согласно такой гносеологической концепции, формируется и вся философская система Соловьева: построение универсальных рациональных схем имеет сверхрациональное основание и базируется на вере в изначальное единство природного, социального и божественного. Это и есть сущность концента «всеединство». Идея всеединства - это не просто символ человеческой культуры, это идеальное представление о безупречно правильной человеческой культуре, культуре, которая не противопоставляет человека ни природе, ни самому лучшему и разумному, что и должно быть для человека божественным и природным. Еще одну характерную черту философской мысли Соловьева исследователи определяют, как практическое качество, порожденное его теоретическим идеалом «всеединства». Это стремление не ограничиваться чисто умозрительными построениями, «выйти из теоретической отвлеченности, школьной замкнутости и заявить верховные права в деле жизни» [14; С.114]. Критика «отвлеченных начал» и интерес к вопросам «практической» философии лежали в основе всей философской системы Соловьева.

В рамках теоретической мысли конца XIX века Соловьев завершает разработку и осмысление таких основополагающих культурфилософских понятий, как: «культура», «цивилизация», «культурно-исторический тип», «нация», «национальная идея», «всечеловечество», чем готовит почву для отечественных культурологических и исторических исследований начала XX века. Соловьев видит культуру как изначальную целостность, как социальный аспект всеединства. Основные идеи, посредством которых Соловьев раскрывает понятие культуры, - это «универсализм», «всеединство», а также «софийность» - принцип триединства Бога, человечества и человека, истины, добра и красоты. София - это больше символическое понятие. Оно рассматривается как женское начало в Боге. София - это Мировая Душа, которая воплощает в себе духовное человечество, лишенное своей материальной природы, чем актуализирует культурно-символическое основание человеческого бытия.

Культура для Соловьева - это форма перерождения материального в человечестве в духовное, средство преображения природы человека и через него - преображение универсума, то есть культура есть активное созидательное творчество человека. Культурное творчество есть деятельность, преобразующая естественное бытие и тем самым формирующая новый миропорядок, созидающая новую реальность перерожденной природы через воплощение в ней сверхприродных начал. Принцип деятельности или деятельностный подход к культуре явился одним из способов постижения этого социального феномена. Мы подчеркнем, что разработка деятельностного подхода во второй половине $\mathrm{XX}$ столетия и начала XXI века стала одним из достижений ленинградско-петербургской философской школы (М.С. Каган [15], [16], Ю.В. Перов [17], Ю.Н. Солонин и др.) [18]. 
Универсализм, всеединство, всечеловечество, софийность - понятия, символизирующие и представляющие культуру как таковую. Важной для последующей философии культуры стала идея Соловьева, утверждающая человечество, народ и семью в качестве доминирующих сфер, в которых происходит культурное становление человека, формирование личности. Вот они, основные понятия-символы национальной культуры. Национальная культура, в свою очередь, является необходимым аспектом и частным проявлением культуры вообще, находя свое отражение в национальном сознании и преломляясь в национальной идее. Национальная идея воплощает в себе основные культурные установки. Формируясь в недрах самой культуры, она может считаться важным культурообразующим фактором, выступая одной из форм культурного и исторического самоосуществления человека, представляя собой одну из фундаментальных культурных инвариант. Итак, укажем в качестве промежуточного вывода, что философия Соловьева представляет собой значительное культурное явление своей эпохи. Она объединяет весь предшествующий опыт исследования культуры в России, завершая и венчая собой культурфилософский анализ XIX века, а также создает почву для последующих изысканий в области культуры и культуротворчества следующего, XX века (символизм, софиология, космизм, евразийство и т.д.).

Философия Соловьева вызвала к жизни мощное культурное движение по духовному преображению мира, социальной революции, проводимой исключительно средствами культуры. В этом плане саму философию Соловьева можно считать символом русской национальной культуры. Если философские искания Соловьева составили основу мировоззренческого символизма, то в области художественной культуры того времени это явление акмеизма, течения, противостоящего символизму и возникшему в начале XX века в России. Известно, что противоположности и противостояние в конечном счете обретают единство, они составляют гармонию.

«Серебряный век» русской национальной культуры это историческое и логическое продолжение «золотого века» отечественной культуры и художественного творчества в целом (Пушкин, Гоголь, Лермонтов, Глинка и др.). «Век» здесь понятие сугубо символическое: начинается он - «серебряный век» в 90-х гг. столетия XIX (поздний Л.Н. Толстой как великий писатель и не менее великий русский философ и религиозный реформатор), а заканчивается в 20-х гг. столетия XX (поэзия футуристов и художников-модернистов). В его рамках значительный интерес по проблеме символизма представляет творчество поэтов и писателей школы акмеизма.

Акмеизм - это культ конкретности, «вещественности» образа, «искусство точно вымеренных и взвешенных слов». Это направление в культуре «Серебряного века» занимает особое место. Оно объединило русских поэтов и писателей рубежа веков (Анна Андреевна Ахматова, Николай Степанович Гумилев, Иванов Георгий Владимирович, Городецкий Сергей Митрофанович, Мандельштам Осип Эмильевич), вышедших и первоначально воспитавшихся в русле творчества символистов (Вяч. Иванов, Мережковский, А. Белый и др.). Поэзия акмеистов замечательна тем, что она «преодолела символизм» и вернулась к точному и ясному слову, достигла сдержанности и лаконичности стиля, строгости и стройности поэтической структуры. В работах представителей этого течения получило необычайное расширение смысловое и символическое пространство текста. Особенностями акмеизма являются возврат к первичному значению слова, и точности образов; изображение реального предметного мира и отказ от мистичности; увлечение предметностью и внимание к деталям; обращение к прошлым культурным эпохам, и восприятие мировой культуры как общей памяти человечества; наконец, проповедь «земного» мироощущения, поэтизация мира первозданной природы.

Как мы отметили, акмеизм возник в противовес символизму, но родился он именно в недрах символизма, потому что поэты-акмеисты учились у символистов стихотворной технике. Они читали свои стихи в «башне» символиста Вяч. Иванова, выслушивали критические замечания старших коллег и поначалу не думали о том, что образуют новое литературное направление. Для акмеистов реальное бытие было ценно само по себе потому, что скрытый смысл вещей, то есть символ, явлен в самих вещах, в земном и реальном бытии. Зримый мир, в понимании акмеистов, запечатлевается в слове, обретает в нём бытийствующий статус. Слово у акмеистов выступает как феномен, обладающий бытием и органической, мироподобной, целостной структурой. Но, может быть, самое главное свойство акмеистов заключается в том, что в отличие от многих деятелей «Серебряного века», они отказывались «пересматривать, видоизменять и дополнять христианство».

Центральные фигуры русского «символизма» В. Брюсов, А. Белый, А. Блок, Д. Мережковский акцентировали значимость того, что неявлено, но угадывается не столько в форме, сколько в развёрнутом в сторону инобытия содержании. При этом реальная жизнь с её бытийными законами начинает терять ценность. В противоположность символистам акмеисты: Гумилёв, Мандельштам, Ахматова вплотную подошли к проблеме соотношения антропологического и идеологического, сознательного и бессознательного, чувственного и рационального, то есть к трактовке жизни и творчества как динамически целостного, органического единства. Они фактически продолжили концепт «всеединства» Соловьева с его ориентацией на универсализм. Акмеистская установка поэтического текста на самопознание с актив- 
ной ролью читателя в «бытии» произведения приводила к изменению роли поэтического субъекта - он становился реальным человеком. Поэтому так важны, с точки зрения традиционной русской культуры, такие сущностные характеристики поэтики акмеизма, как ориентация на земные ценности, утверждение самоценности бытия во всех его формах и проявлениях, познание онтологических, культурных и психологических феноменов. Акмеисты, осмысляя историю, культуру, искусство, значительно повлияли на развитие русской и мировой культуры $\mathrm{XX}$ столетия в целом.

Символизм актуализировал распад бытия в мировоззренческом и в художественном смыслах, тогда как акмеизм стремился к его художественно-онтологическому воссозданию. Бытие здесь рассматривалось как целостность - сторонами которого выступает и Природа с её первозданной и божественной красотой, и Общество с его культурой, и Человек как личность, личность неповторимая как Микро-космос. Идея универсализма обретала свое новое бытие в историческом контексте двадцатого века.

Выраженные в символизме интенции к постижению трансцендентного, проникновение за грань феноменального и «тоска по целостности» проявляется в художественной форме, созданной по иным, «не традиционным», «не бытийным» законам. В отличие от символистов, акмеистов волновало бытие, познаваемое через Слово в его библейском формообразующем смысле. В связи с этим акмеисты провозглашали органическую целостность Мира и Человека. Произведения искусства понимались ими в свете «органиче- ской поэтики» и «философии слова». Художественные произведения, по их убеждению, рождаются и живут, обретая бытие по подобным всему сотворенному Богом законам. Постигая органическую целостность бытия, человечество, таким образом, приобщается к тайне божественной гармонии, выраженной языком искусства. А символ, несмотря на его сверхчувственную основу, становится земным и бытийным знаком и образом.

В качестве общих выводов укажем, что, во-первых, философия В.С. Соловьева знаменовала собой тождество принципа универсализма в истории отечественной философии, понимаемого как «всеединство»; в этом всеединстве особое место принадлежит концепту «софийность» как выражению символического начала, где София (Мудрость) - Мировая Душа, надприродное начало человеческого бытия ; во-вторых, символизм и акмеизм, развиваясь в одном культурно-историческом пространстве «Серебряного века», феномен бытийной и художественной целостности, осмысливали различно: либо с позиций ухода в трансцендентное (символизм), либо обращались к бытию конкретного человека как личности; в-третьих, символизм явился предтечей акмеизма, а акмеизм - последствием символизма, следовательно, и символизм, и акмеизм в своем единстве представляли то, что можно определить как органичность содержания русской художественной культуры «Серебряного века»; наконец, в-четвертых, универсализм мировоззренчески - художественной позиции лидеров акмеизма, их интерес к бытию Природы мы можем рассматривать как истоки экологической проблематики русского космизма XX века и евразийства.

\section{ЛИТЕРАТУРА}

1. Корольков А.А. Духовная антропология / А.А. Корольков. - Санкт-Петербург : Издательство Санкт-Петербургского университета, 2005. - 323 с.

2. Жданов Ю.А. Отдай себя духу (из поэтических тетрадей) / Ю.А. Жданов. - Ростов н /Дону: ИППК, 2006. - 72 с.

3. Абрамов Ю.Ф. Феномен духовности в глобализирующемся обществе / Ю.Ф. Абрамов, Р.А. Косолапов, В.И. Куйбарь // Известия Иркутского государственного университета, 2015. - Т. 11. - С. 169-171

4. Маркарян Э.С. О значении разработки основ общей культурологической теории для формирования идеологии самосохранения человечества / Э.С. Маркарян. - Текст : электронный // Мосолова Л.М. Культурология и глобальные вызовы современности. - URL : http://litra.pro/kuljturologiya-i-globaljnievizovi-sovremennosti/mosolova-I-m/read/16 (дата обращения: 10.06.2020)

5. Арефьев М.А. Особенности социального порядка во взаимодействии языковых культур в русской и тюркской народных традициях: монография / М.А. Арефьев, А.В. Зыкин, А.О. Туфанов. - Санкт-Петербург: Издательство СПбГАУ, 2016. - 95 с.

6. Тайлор Э.Б. Первобытная культура / Э.Б. Тайлор. - Москва: Политиздат, 1989. - 572 с.

7. Булгаков С.Н. Что дает современному сознанию философия Владимира Соловьева? / С. Н. Булгаков // Книга о Владимире Соловьеве. - Москва, 1991. - С. 389-448

8. Бердяев Н.А. Проблема Востока и Запада в религиозном сознании В.С. Соловьева / Н.А. Бердяев // Книга о Владимире Соловьеве. - Москва, 1991. - С. 355-374

9. Лосев А.Ф. Соловьев и его время / А. Ф. Лосев. - Москва : Молодая гвардия, 2000. - 614 с.

10. Мочульский К.В. Владимир Соловьев: жизнь и учение / К.В. Мочульский // В.С. Соловьев: Pro et contra. - Санкт-Петербург, $2000 .-617$ с.

11. Трубецкой Е.Н. Владимир Соловьев и его дело / Е.Н. Трубецкой // Книга о Владимире Соловьеве. - Москва, 1991. - С. $637-661$

12. Эрн В.Ф. Гносеология В.С. Соловьева : публицистика / В.Ф. Эрн. - Москва : Директ-Медиа, 2012. - 78 с. 
13. Бердяев Н.А. Проблема Востока и Запада в религиозном сознании В.С. Соловьева / Н. А. Бердяев // Книга о Владимире Соловьеве. - Москва, 1991. - С. 363

14. Соловьев В.С. Кризис западной философии (против позитивистов) / В.С. Соловьев // Соловьев В.С. Полное собрание сочинений и писем в 20 т. -Москва, 2000 - T. 1. - С. 114

15. Каган М.С. Философия культуры / М.С. Каган. - Санкт- Петербург : Петрополис, 1996. - 414 с.

16. Каган М.С. Философская теория ценности / М.С. Каган. - Санкт- Петербург : Петрополис, 1997. - 204 с.

17. Перов Ю.В. К вопросу о «метафизических» предпосылках философии ценностей / Ю.В. Перов // Историчность и историческая реальность. - СанктПетербург: Санкт- Петербургское философское общество, 2000. - (Мыслители. - Выпуск 2). - С. 117-131

18. Солонин Ю.Н. Смысл философии ценностей как науки / Ю.Н. Солонин, С.И. Дудник // Аксиологические проблемы научной и технической реальности: тезисы научной конференции, Санкт-Петербург, 28-29 января1998. - Санкт-Петербург, 1998. - 137 с.

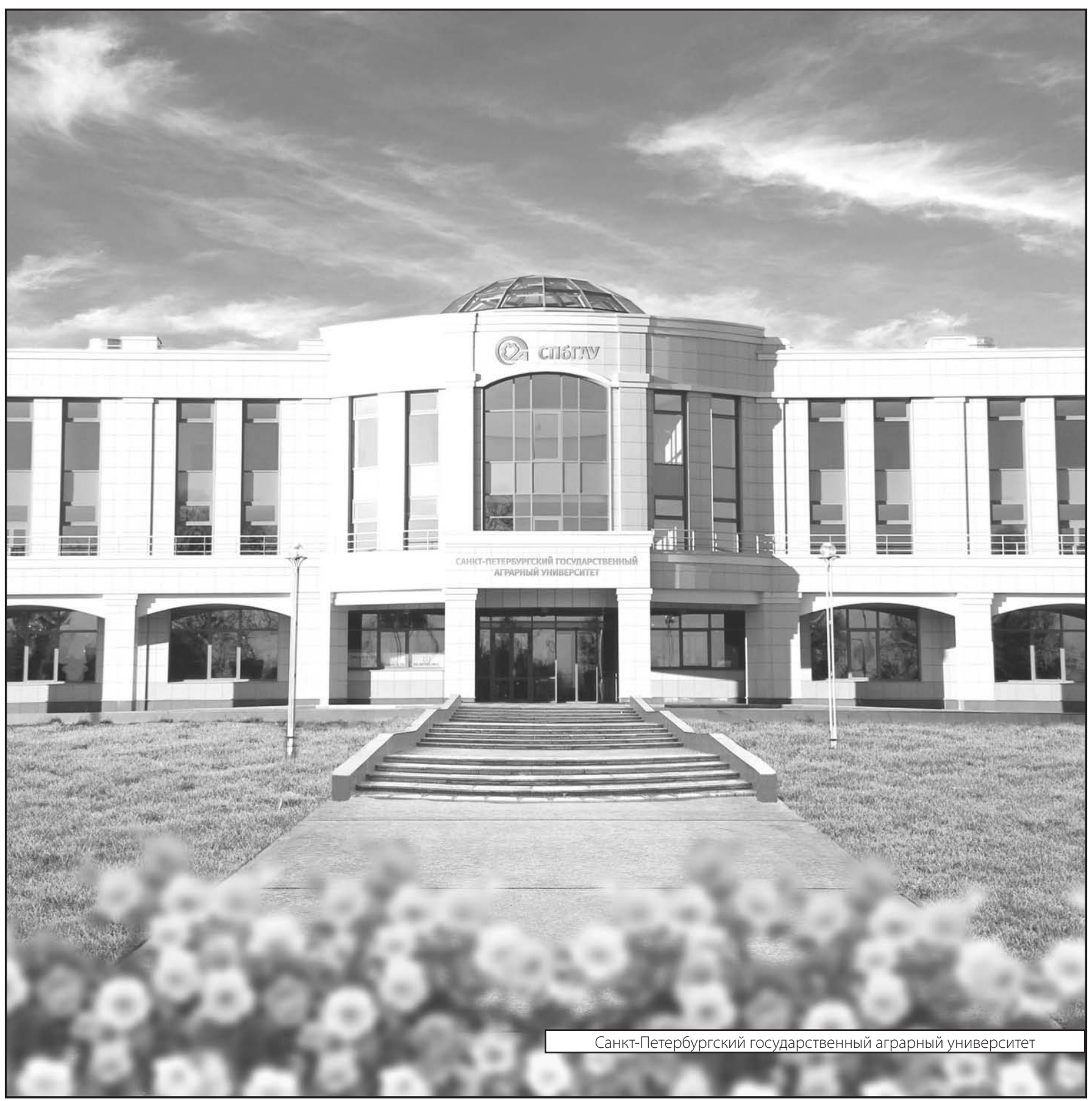

